\title{
CYCLOOXYGENASE-2 EXPRESSION IN COLORECTAL CANCER IN NORTH INDIA- A PILOT STUDY
}

\author{
Arundhati $^{1}$ \\ ${ }^{1}$ Consultant Pathologist, Mahavir Cancer Sansthan and Research Institute, Patna.
}

ABSTRACT
BACKGROUND
The aim of the study is to evaluate cyclooxygenase $-2(\mathrm{COX}-2)$ expression in cases of sporadic cancer cases of colorectum. COX-2 is
an important enzyme involved in inflammation, so in future COX-2 inhibitor could be used in the treatment of chronic
inflammation of these organs as well as malignancies.

\section{MATERIALS AND METHODS}

Total number of 29 cases of colorectal cancer were studied in a period of one year. In this study, COX-2 expression is assessed by immunohistochemistry.

\section{RESULTS}

In our study, 15 males and 14 females were affected constituting almost equal ratio. Most of the cancers were seen in sixth decade of life. The mean age in the colon cancer is $46 \pm 3.08$ years respectively. COX- 2 expression is seen in $80 \%$ cases of colorectal cancer and approximately $87.5 \%$ positive cases had either moderate or strong staining.

\section{CONCLUSION}

Thus, our study concluded that COX-2 inhibitors can be effective in treatment of cases of colorectal cancer along with other drugs, because $70 \%$ of these malignancies express COX-2.

\section{KEYWORDS}

Cyclooxygenase-2, Colorectal Carcinoma.

HOW TO CITE THIS ARTICLE: Arundhati. Cyclooxygenase-2 expression in colorectal cancer in north India- A pilot study. J. Evolution Med. Dent. Sci. 2017;6(43):3355-3358, DOI: 10.14260/Jemds/2017/726

\begin{abstract}
BACKGROUND
Worldwide it is estimated that about $20 \%$ of all deaths are cancer related. A lot of clinical and experimental research and epidemiological studies have been carried out in the field of Oncology so as to know the possible cause of cancer and mechanism involved in transformation of normal cell into neoplastic cell. Worldwide colorectal cancer is a very common malignant tumour of the digestive tract, and ranks third most common in men $(663000$ cases, $10.0 \%$ of all cancer cases) and the second most common in women (571000 cases, $9.4 \%$ of all cancer cases).[1] Worldwide each year about 1.2 million new cases and 600000 deaths occur because of colorectal cancer.[2] In India, the annual incidence rates (AARs) for colon cancer and rectal cancer in men are 4.4 and 4.1 per 100000 , respectively. The AAR for colon cancer in women is 3.9 per 100000 . Colon cancer ranks $8^{\text {th }}$ and rectal cancer ranks $9^{\text {th }}$ among men in India.[3] Aetiopathogenesis of these malignancies are not well understood. Chronic inflammation, chronic irritation, premalignant lesions, dietary factors and other environmental factors have been blamed as aetiological factors. Amongst these the role of chronic inflammation in producing malignancy is very strong.
\end{abstract}

Financial or Other, Competing Interest: None.

Submission 28-04-2017, Peer Review 20-05-2017,

Acceptance 22-05-2017, Published 29-05-2017.

Corresponding Author:

Dr. Arundhati,

Consultant Pathologist,

Department of Pathology,

Mahavir Cancer Sansthan,

Patna (Bihar) India.

E-mail: ashok_74_kumar@Yahoo.co.in

DOI: $10.14260 /$ jemds $/ 2017 / 726$
Earlier studies have shown that in colorectal cancer, increased expression of COX-2 is found in up to $85 \%$ of cases but not in normal colonic epithelium. ${ }^{[4,5]}$

Cyclooxygenase (COX) is the enzyme that catalyses the conversion of arachidonic acid to prostaglandins and is involved in several biological pathways.

It has two isoforms: COX-1 is constitutively expressed in tissues and is helpful in maintenance of gastric mucosa, regulation of renal blood flow and platelet aggregation. COX-2 is an inducible enzyme and produces prostaglandins in response to inflammatory stimulus or growth factors. COX-2 overexpression has been associated with many neoplastic and preneoplastic conditions, inhibition of apoptosis, increased metastatic potential and neoangiogenesis. Furthermore, expression of COX-2 is elevated in a variety of human carcinomas and suppression of COX-2 reduces tumour development.

In this research work, COX-2 expression has been studied immunohistochemically in colorectal cancer and its expression has been tried to correlate with grade of these tumours, so that this study could add to what we already know about the importance of COX-2 and its association with colorectal cancer and its pathogenesis. It could help in opening new vistas to the future therapeutic agents for the treatment and chemoprevention of these tumours.

\section{Aim of the Study}

1. To find out the expression of COX-2 enzyme by immunohistochemistry in malignant tumours of colorectal cancer in North India.

2. Correlation of COX-2 expression with the grade of the tumour. 


\section{MATERIALS AND METHODS}

In this descriptive study, 29 cases of colorectal cancer was taken along with self-control of nonmalignant tissue. Sample size was taken conveniently. Though similar type of study has been done from different areas of world but from Bihar and eastern Uttar Pradesh of India no such study has been done. All these patients were examined clinically for their presenting complaints, and clinical examination was supported by some routine tests, radiological, endoscopic, histopathological and immunohistochemical examinations. Diagnosis of malignancy was confirmed by histopathology. Demonstration of COX-2 in tissue was done by indirect immunoperoxidase method. This method employed a mouse monoclonal antibody (NCL-COX-2) of Vision Biosystems, Novocastra ${ }^{\mathrm{TM}}$ as primary antibody and secondary antibody of Ultra Tech HRP (DAB) Streptavidin Biotin Detection System from Beckman Coulter was used. The paraffin sections were cleared in xylene, then passed in $90 \%, 70 \%$ alcohol, then brought to running water. Sections were treated with $3 \%$ $\mathrm{H}_{2} \mathrm{O}_{2}$ in methanol for 10 minutes to block endogenous peroxidase. Antigen retrieval was done by boiling tissue in $0.1 \mathrm{M}$ citrate buffer at $\mathrm{pH} 6.0$ for 10 minutes. Sections were washed in running water. Blocking agent was poured for 10 minutes. It was drained and incubated with monoclonal antibody to COX-2 diluted in 1:20 in 0.6 \% BSA for 1 hour. Sections were washed in PBS $0.01 \mathrm{M}$ for 15 minutes \& incubated with streptavidin peroxidase for 30 minutes. Slides were washed in PBS \& incubated with fresh DAB solution (3,3'-DAB $5 \mathrm{mg}+$ PBS $\left.5 \mathrm{~mL}+10 \mu \mathrm{L} \mathrm{H}_{2} \mathrm{O}_{2}\right)$ for 10 minutes in dark. Sections were washed in running water and stained with Mayer's Haematoxylin for 2 minutes. Sections were washed in running water, dehydrated in alcohol, cleared in xylene and mounted in DPX.
The Positive Stained Areas were Expressed as the Percentage of the Whole Cancer Area and Scored as-

0 - None.

$1-0-25 \%$.

$2-26-50 \%$.

$3->50 \%$.

\section{Statistical Analysis}

All the data were analysed with statistical software (Graphpad Prism 5) and values were expressed with p value using column contingency, Chi Square Test (and Fisher exact Test) analysis. We considered $\mathrm{p}<0.05$ as a statistically significant value.

\section{RESULTS}

In our study, colorectal carcinoma showed almost equal sex prevalence similar to finding. The mean age of colorectal carcinoma is $46 \pm 3.08$ years. Largest number of colorectal patients are in age range of 21-40 years (Figure: 1 ). In our study, $80 \%$ cases of colorectal carcinomas showed varying degree of cytoplasmic COX-2 positivity which corresponded very much to the findings of Wu et al in $2015^{[6]}$ who had similar observation of overexpression of COX-2 in $77.97 \%$ cases of colonic adenocarcinomas. In our study, $71.42 \%$ cases of well-differentiated adenocarcinoma of colorectum showed positivity for COX-2 (Figure: $2 \& 3$ ), whereas all cases of moderately (Figure: 4) and poorly differentiated adenocarcinoma of colorectum showed positivity for COX-2 (Table: 1). As sample size is small, we cannot say very confidently that COX-2 overexpression is associated with poorly differentiated adenocarcinomas \& it may be a mere coincidental finding. We summarised several pathological characteristics of the tumour in association with COX-2 expression in Table 1. On analysis value is found to be $\mathrm{P}=0.0001$ which is statistically significant.

\begin{tabular}{|c|c|c|c|c|c|c|c|c|c|c|}
\hline \multirow{3}{*}{ Groups } & \multirow{3}{*}{$\begin{array}{l}\text { Total No. } \\
\text { of Cases }\end{array}$} & \multirow{3}{*}{$\begin{array}{l}\text { No. of COX-2 } \\
\text { Positive } \\
\text { Cases }\end{array}$} & \multirow{3}{*}{$\begin{array}{l}\text { (\%) of COX-2 } \\
\text { Positive Cases }\end{array}$} & \multicolumn{6}{|c|}{ Grade of positivity } & \multirow{4}{*}{ p value } \\
\hline & & & & \multicolumn{2}{|c|}{ Weak } & \multicolumn{2}{|c|}{ Moderate } & \multicolumn{2}{|c|}{ Strong } & \\
\hline & & & & No. & $\%$ & No. & $\%$ & No. & $\%$ & \\
\hline Colorectal cancer & 29 & 24 & 82.75 & 3 & 12.5 & 12 & 50 & 9 & 37.5 & \\
\hline \multicolumn{10}{|c|}{ Histological Types of Colorectal Cancer } & \\
\hline $\begin{array}{c}\text { a. Well-differentiated } \\
\text { carcinoma }\end{array}$ & 20 & 15 & 75 & 3 & 20 & 6 & 40 & 6 & 40 & \multirow{3}{*}{0.0001} \\
\hline $\begin{array}{c}\text { b. Moderately } \\
\text { differentiated carcinoma }\end{array}$ & 6 & 6 & 100 & 0 & 0 & 4 & 67 & 2 & 33 & \\
\hline $\begin{array}{l}\text { c. Poorly differentiated } \\
\text { adenocarcinoma }\end{array}$ & 3 & 3 & 100 & 0 & 0 & 2 & 67 & 1 & 33 & \\
\hline
\end{tabular}

Table 1. Correlating Number and Grade of Colorectal Cancer with COX-2 Expression and its Intensity $(p<0.05)$

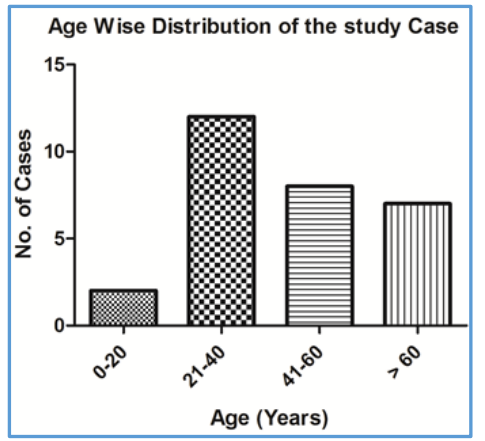

Figure 1. Bar Diagram Showing Distribution of Colorectal Cases Age Group wise

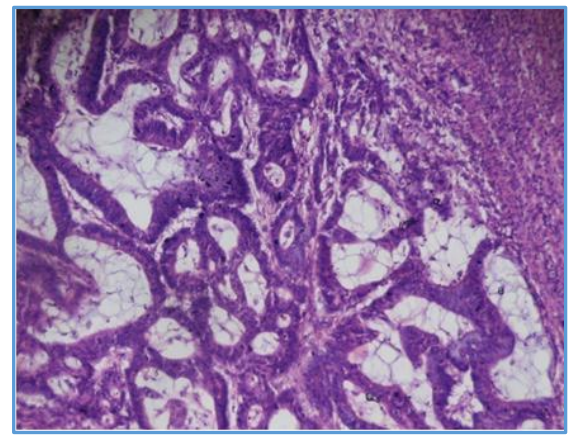

Figure 2. Well-differentiated Adenocarcinoma Colon H \& E x400 


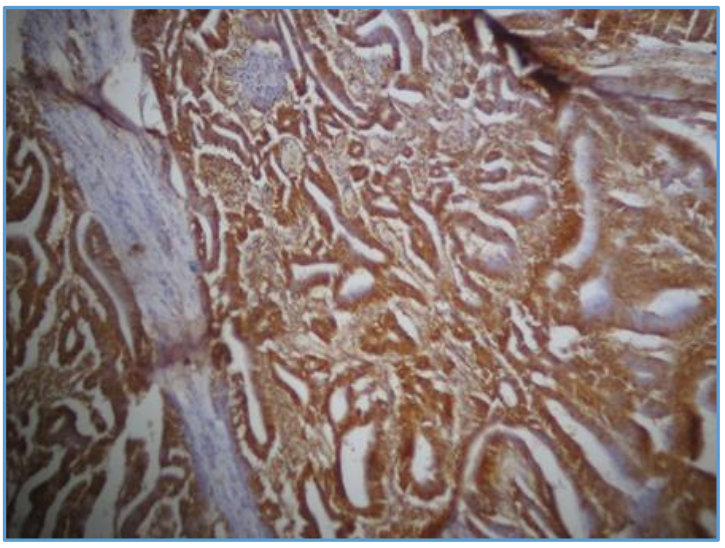

Figure 3. Immunoperoxidase Staining of COX-2 of WellDifferentiated Carcinoma Colon, There is Intense Cytoplasmic Staining of Malignant Cells x100

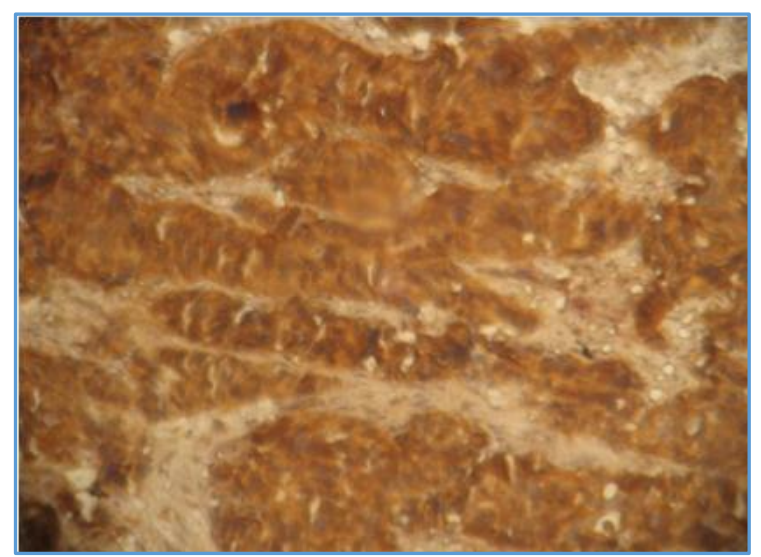

Figure 4. Immunoperoxidase Staining for COX-2 in Moderately Differentiated Adenocarcinoma of Colon Showing Strong Cytoplasmic Staining x400

\section{DISCUSSION}

The mean age of colorectal carcinoma is $46 \pm 3.08$ in the studied population of North India (Eastern Uttar Pradesh and Bihar), which is pretty less as compared to western world. The average age of CRC patients in the United States is 67 years.[7] In Western countries, the prevalence of CRC in patients less than 50 years old ranges from $2 \%$ to $8 \% .{ }^{[8,9]}$

Ebehart et al in 1994 found in their study that COX-2 progressively overexpressed during the stepwise sequence from adenoma to carcinoma. Our study also showed similar results that COX-2 expression progressively increased \& was persistent as the differentiation of the tumour became poorer.[10]

COX-2 is not or is lowly expressed in normal tissues; however, COX-2 expression is increased in inflammatory and tumour tissue and plays an important role in inflammation, cell proliferation and differentiation, suggesting that COX-2 is involved in the initiation and progression of cancer. Brown et al[11] in their study concluded that regulation of COX-2 expression is a key step in colorectal carcinogenesis. COX-2 is a potential biomarker of cancer risk, and COX-2 inhibitors may prevent colon cancer. Kraus et al[12] in their animal experiments showed that COX-2 inhibitors prevent the formation of adenomas or delay their development, and reduce the morbidity and mortality of colorectal cancer. However, cancer prevention is still being ignored in the cancer research field. Targeted drug therapy in colorectal cancer based on the expression of COX-2 along with other modalities of treatment can be considered.

Nonsteroidal anti-inflammatory drugs (NSAIDs) have been shown to protect against several tumours, such as colorectal cancer, which leads to a hypothesis that it comes at least partly from inhibiting the activity of the COX enzymes (Thun et al, 2002). The involvement of COX-2 in carcinogenesis has been shown in many epidemiological, animal \& clinical studies, and COX-2 inhibitors have been proved to be effective in suppressing tumour progression both in vitro and in vivo in nude mice.[13,14] Individuals who took NSAIDs regularly had a markedly reduced risk of developing colon cancer.[15]

\section{CONCLUSION}

Thus, our study concludes that cancers of colon are probably secondary to inflammatory pathology. Hence, control of inflammation may reduce the frequency of these cancers.

To date major emphasis has been placed on evaluating the role of selective COX-2 inhibitors in preventing cancer. Now there is growing interest in finding out whether these agents are also useful in treating cancer. In most preclinical studies, selective COX-2 inhibitors reduced the growth of established tumours rather than causing tumour regression. This suggests that selective COX-2 inhibitors will be most beneficial when administered in combination with standard therapy. This idea is supported by several experimental studies in which the efficacy of chemotherapy or radiotherapy was enhanced by co-treatment with a selective COX-2 inhibitor. Whether the same will prove to be true in human beings also awaits further investigation.

\section{REFERENCES}

[1] GLOBOCAN 2008 (http://globocan. iarc.fr/factsheets/ cancers/colorectal.as 2008.

[2] Raskov H, Pommergaard HC, Burcharth J, et al. Colorectal carcinogenesis--update and perspectives. World J Gastroenterol 2014;20(48):18151-64.

[3] NCRP (2013). Three-year report of the population based cancer registries, 2009-2011. National cancer registry programme, Indian council of medical research (ICMR), Bangalore, India, 2013.

[4] Taketo MM. Cyclooxygenase-2 inhibitors in tumorigenesis (Part I). J Natl Cancer Inst 1998;90(20):1529-36.

[5] Taketo MM. Cyclooxygenase-2 inhibitors in tumorigenesis (Part II). J Natl Cancer Inst 1998;90(21):1609-20.

[6] Wu QB, Sun GP. Expression of COX-2 and HER-2 in colorectal cancer and their correlation. World J Gastroenterol 2015;21(20):6206-14.

[7] Wallace JL, Devchand PR. Emerging roles for cyclooxygenase-2 in gastrointestinal mucosal defense. Br J Pharmacol 2005;145(3):275-82.

[8] Oshima M, Dinchuk JE, Kargman SL, et al. Suppression of intestinal polyposis in Apc delta716 knockout mice by inhibition of cyclooxygenase 2 (COX-2). Cell 1996;87(5):803-9.

[9] Keller JJ, Giardiello FM. Chemoprevention strategies using NSAIDs and COX-2 inhibitors. Cancer Biol Ther 2003;2(4 Suppl 1):S1409-9. 
[10] Eberhart CE, Coffey RJ, Radhika A, et al. Up-regulation of cyclooxygenase 2 gene expression in human colorectal adenomas and adenocarcinomas. Gastroenterology 1994;107(4):1183-8.

[11] Brown JR, DuBois RN. COX-2: a molecular target for colorectal cancer prevention. J Clin Oncol 2005;23(12):2840-55.

[12] Kraus S, Naumov I, Arber N. COX-2 active agents in the chemoprevention of colorectal cancer. Recent Results Cancer Res 2013;191:95-103.
[13] Thun Mj, Henley SJ, Patrono C. Nonsteroidal antiinflammatory drugs as anticancer agents: mechanistic, pharmacologic and clinical issues. J Natl Cancer Inst 2002;94(4):252-66.

[14] Thun Mj, Namboodiri MM, Health CW. Aspirin use and reduced risk of fatal colon cancer. $\mathrm{N}$ Engl J Med 1991;325(23):1593-6.

[15] Church RD, Fleshman JW, McLeod HL. Cyclooxygenase 2 inhibition in colorectal cancer therapy. $\mathrm{Br} \mathrm{J}$ Surg 2003;90(9):1055-67. 